\title{
Contrato sobre bienes de Propios de las Corporaciones locales
}

por

\author{
ALBERTO VERA FERNANDEZ-SANZ \\ Secretario de $1 .^{a}$ categoria de Administración Local
}

Sumario: Introducción: I. Los bienes de propios: A) Concepto; B) Naturaleza juridica; C) Su regulación juridica.-II. Las relaciones contractuales sobre ios bienes de propios: A) Elementos subjetivos; B) Elementos objetivos: a) Contratos instrumentales; b) Contratos sobre montes privadoc; c) Contratos sobre bienes rústicos; d) Contratos sobre bienes relacionados con la ordenación urbana; $e$ ) Contratos sobre bienes de propios destinados al púb!ico: bares y restaurantes, salas de espectáculos, hoteles, plazas de toros. C) Elementos formales; D) Pérdida de efectos de los contratos por anulación.

\section{INTRODUCCIÓN}

El objeto del presente trabajo ofrece el interés de pertenecer a una materia que se encuentra, digámoslo así, a caballo entre el Derecho civil y el administrativo, regulada por ambos ordenamientos. Es un tema eminentemente práctico, y por ello lo hemos realizado a través de los fallos jurisprudenciales del Tribunal Supremo, Decretos resolutorios de Competencia y Decisiones de la Dirección de Registros, prescindiendo de la doctrina bibliográfica.

Partimos del criterio más comúnmente aceptado de distinción entre contratos civiles y administrativos, atendiendo al objeto: cuando éste es un bien privado de la Administración pública, el contrato en principio, es civil. $\mathrm{Y}$ decimos en principio 
porque, como veremos, abunda en la Jurisprudencia la opinión contraria, principalmente cuando dichos bienes se destinan a una función pública.

\section{i. LOS BIENES DE PROPIOS}

\section{A) Concepto}

Según el artículo 5. ${ }^{\circ}$ del Reglamento de Bienes de las Corporaciones locales de 27 de mayo de 1955 , se pueden definir los bienes de propios, como aquellos que siendo patrimoniales, es decir, perteneciendo a las Corporaciones en régimen de Derecho privado, pueden constituir fuente de ingresos de tal naturaleza para el erario local.

Análogo concepto habia dado con anterioridad a dicho Cuerpo reglamentario el Tribunal Supremo. Así, en sentencia de 17: de diciembre de 1904, califica como tales: "...aquellos que perteneciendo a las ciudades o pueblos, den algún fruto o renta en beneficio del procomún, beneficio o producto que ingresa en las arcas municipales, pero del que nadie en particular, ningún vecino aisladamente, puede usar". Y la sentencia de 3 de marzo de 1934 (Sala 4), destaca ırademás de la pertenencia y posesión a la Entidad local, y que no se hallen destinados al aprovechamiento común, el que el Ayuntamiento los aplique a sus necesidades y a servir de ingresos o recursos al presupuesto municipal para cubrir atenciones del mismon.

\section{B) Naturaleza jurídica}

Los bienes de propios son auténticas propiedades privadas de las Corporaciones locales. Es decir, "cosas" de naturaleza patrimonial distinta, según el artículo 343 del Código civil, de los llamados bienes de uso público, según el propio artículo, y de los de dominio público, expresión más feliz y comprensiva del artículo 2. del Reglamento de Bienes. Dos notas destaca el Tribunal Supremo para caracterizar la naturaleza específica: de una parte, la patrimonialicad; de otra, la naturaleza del producto (S. 9-II-1956). 
Ahora bien, el hecho de que constituyan un ingreso o renta para la Corporación, no debe llevar a confundirlos con otros ingresos de distinta naturaleza como son los arbitrios.

Desde antiguo, ya una Circular de 28 de julio de 1853, al efecto de sujetar al pago del 20 por 100 del producto de la enajenación de propios, deslindaba unos y otros, considerando arbitrios los derechos que muchos pueblos tienen o pueden establecer con facultad competente sobre ciertos géneros, artículos, ramos, etc., para satisfacer sus cargas, cubrir sus gastos o atender a otros objetos análogos de pública utilidad.

Si bien a los efectos del pago de dicha participación al Estado, ya suprimida, ha perdido interés la cuestión, está patente ia diferencia hasta el punto de que el Decreto-ley de Haciendas locales de 25 de enero de 1946 en su artículo 18 advertía que deben considerarse bienes de propios "aquellos que produzcan al Municipio ingresos que constituyan renta, no considerándose tal el producto de la exacciones locales o tarifas de servicios públicos municipales", y así dice la sentencia citada (9-II-1956) "que no lo serán sino aquellos que producen rentas, entendiendo por tales los frutos naturales, civiles e industriales a que se refiere el artículo 354 del Código civil, y que corresponde a bienes privados y no a exacciones impuestas por función de autoridad".

\section{C) Su regulación juridica}

Determinada la naturaleza de los bienes que nos ocupan, hemos de delimitar qué normas son aquellas por las que se rigen. Esto tiene su importancia no sólo doctrinal, sino también práctica, puesto que de su sometimiento en bloque al Derecho público o al privado, dependerá en gran medida que las relaciones contractuales que sobre ellos recaigan, queden bajo la órbita de uno $u$ otro ordenamiento.

Es evidente que en cuanto propiedad privada con una finalidad no inmediatamente pública se rigen por las normas del Código civil, no sólo como normas subsidiarias en virtud del principio general formulado en su artículo 16, sino como normas directas a tenor del párrafo segundo del artículo 344 ulos demás bienes son patrimoniales y se regirán por las disposiciones de este Códigon, que deja a salvo lo que dispongan las leyes especiales. 
El propio artículo 5..$^{\circ}$ del Reglamento de Bienes se refiere al régimen de Derecho privado. Es decir, que habrá que estar tanto a las normas del Código civil, como a las de las leyes especiales, en este caso la Ley de Régimen local y el citado Reglamento.

Estas últimas normas atañen, principalmente, a determinados requisitos formales a que se sujetan los bienes patrimoniales por razón del sujeto al que pertenecen, y que en conjunto responden al principio de tutela administrativa. Dichos poderes de tutela se manifiestan no sólo en las autorizaciones y aprobaciones, sino también en la obligatoriedad de ciertos requisitos en la actividad de los Entes descentralizados territorialmente para salvaguarda del interés público. Ejemplos de ello los encontramos en diversos artículos del Reglamento de Bienes: "Artículos 11 y 12: requisitos para la adquisición de bienes a título oneroso; de inmuebles: informe previo pericial y acuerdo de la Corporación ; de muebles : autorización del Ministerio de Hacienda y del de Gobernación; de bienes de valor histórico, etc.: informe previo del Ministerio de Educación Nacional; artículo 16: obligatoriedad de formar inventario; artículo 35 : obligatoriedad de inscripción en el Registro de la Propiedad, que tiende a impedir el ejercicio de acciones contra las Corporaciones al amparo del artículo $\mathbf{4 1}$ de la Ley Hipotecaria; artículo 75: obligatoriedad de subasta en arrendamientos de bienes patrimoniales; artículo 95: necesidad de autorización para enajenar, permutar inmuebles de propios; artículo 97: condiciones a que se sujetan las cesiones de bienes patrimoniales; artículo 98: subasta para enajenación de bienes de propios; artículo 103: valoración técnica como requisito previo a toda enajenación de bienes patrimoniales por la que se acredite fehacientemente su justiprecio; artículo 104: autorización del Ministerio de Hacienda para enajenar o pignorar láminas o valores mobiliarios que la concederá o denegará, visto el dictamen de la Dirección General de la Deuda y Clases Pasivas. 


\section{LAS RELACIONES CONTRACTUALES SOBRE LOS BIENES DE PROPIOS}

\section{A) Elementos subjetivos}

Obvio es decir que en los tipos contractuales que examinamos es necesaria la presencia de una Corporación local como parte contratante, entendiendo por tales aquéllas que así reconoce la. Ley de Régimen local en su artículo $4 .^{\circ}$ : Ayuntamientos, Diputaciones y Juntas vecinales, a las que el artículo $6 .^{\circ}$ reconoce plena capacidad para celebrar contratos.

En este punto, nos interesa examinar dos cuestiones sobre las que se ha pronunciado la Jurisprudencia: 1) Necesidad de que contrate una Corporación local, y 2) Carácter con que intervienen las Corporaciones.

1) Es preciso que figure como contratista una Corporación, y que el contrato se celebre por el órgano competente según la Ley. El Tribunal Supremo, en sentencia de 4 de diriembre de 1925 , nos dice que "...lo primero que diferencia los actos y contratos civiles de los administrativos es de esencia que una de las partes sea la Administración, que interviene en ellos como parte, y en virtud de ese contrato impone condiciones que ponen a salvo su peculiar prerrogativa de poder". Y mantuvo la misma doctrina en la sentencia de 30 de abril de 1927 (Sala 3), al surgir la Exposición de Industrias Madrileñas en reunión celebrada entre el Alcalde de Madrid y los representantes de las fuerzas vivas, y concedida autorización por su Ayuntamiento para que pudiera celebrarse en el Parque de Madrid, se confeccionó por su arquitecto municipal el proyecto definitivo, con arreglo al cual el Alcalde contrató con los arquitectos la construcción del edificio principal. Surgidas diferencias sobre el pago de gastos, el Tribunal Supremo mantuvo u...que el vínculo jurídico surgido no es. administrativo ni verdadero acto de la Administración...", porque el Comité ejeeutivo estaba constituido por personas integrantes de las llamadas fuerzas vivas, entre las que figuraba alguna que tenía cargo público, pero no lo eran todas, y como en su conjunto tampoco implica ninguna de las Entidades u organismos creados en las distintas ramas de la Administración pública para cumplimiento de servicios 
de esta naturaleza, no puede ser considerada como persona o Entidad administrativa.

2) La segunda cuestión nos muestra una evolución en la doctrina jurisprudencial.

La Decisión de Competencia más antigua que hemos recogido (7-4-1865), atribuye a las Corporaciones el carácter de personas jurídicas y no de Entidades administrativas. Id. R. D. de Competencia de 14 de noviembre de 1878 . Otro $R$. D. de Competencia de 21 de diciembre de 1880 , declara que al ceder un Ayuntamiento ciertos terrenos a censo enfitéutico, no obró como Corporación administrativa, sino ejercitando derechos civiles, y si al ejercitarlos lesiona los de un particular, puede éste reciamar en via ordinaria. $Y$ más confusa es la sentencia de 28 de septiembre de 1886 , que califica de índole civil los contratos en que la Administración interviene como persona jurídica, esto es, como sujeto de derechos y obligaciones..., y no obró el Ayuntamiento como administrador de sus bienes propios y en beneficio exclusivo de ellos, y carece por tanto del carácter de persona juridica. Otro R. D. de Competencia de 8 de octubre de 1889: “...la autoridad que lo celebró no pudo mitenos de obrar como autoridad administrativa de los intereses de la Provincia, y no como persona jurídica determinada". Tampoco es afortunada la sentencia de 30 de octubre de 1909, referente al arriendo del Teatro Principal de Zaragoza, de propiedad municipal, "para decidir el punto principal del pleito, o sea ía competencia del Gobernador o del Tribunal Contencioso para conocer del contrato, es preciso examinar las dos maneras en que los Ayuntamientos intervienen en sus contratos, ya obrando como partes de la Administración cuando el objeto de aquéllos son los arriendos sobre servicios públicos, ya cuando obran como personas jurídicas al contratar sobre cosas de su propiedad, no siendo en este caso la legislación administrativa la que ha de regular el contrato...". En otra ocasión (S. de la Sala 3 de 20-3-1926), se dice que el contrato es civil porque obra al celérarlo como persona jurídica y no como poder social. El mismo calificativo se emplea en otra ocasión por la Sala 1 en sentencia de 25 de octubre de 1951, sobre nulidad de contratos por venta de terrenos destinados a estadio municipal, 
se allegó la incompetencia de la Jurisdicción ordinaria, que el Tribunal Supremo rechazó, considerando "que se han fijado como criterio de distinción el carácter con que interviene en ellos la Administración, pues en los administrativos lo hace a modo de poder, imponiendo como tal, condiciones que dejan a salvo sus peculiares prerrogativas, o que como dice el auto recurrido, más que contratar puede decirse que manda, viendo en el particular un subordinadon.

La más reciente sentencia que hemos manejado tampoco demuestra que el criterio del Tribunal Supremo se halla clarificado. En la sentencia de la Sala 4 de 19 de diciembre de 1958 uinterviene la Corporación con el carácter de persona juridica particular sujeta à derechos y obligaciones, alejada por completo de la naturaleza administrativan.

Sólo en un fallo (S. 28-12-1942), la Sala de lo civil empleó un calificativo más adecuado. Con referencia a la permuta por el Ayuntamiento de una parcela de terreno destinada a la apertura de dos calles, por otras dos parcelas uque califica de civil, puesto que la Corporación actuó como persona jurídica privada en plano de igualdad al crear un vínculo que entra de lleno en la esfera del Derecho privadon.

De todas estas decisiones, sacamos en conclusión la imprecisión con que se ha calificado la intervención de la Administración pública en las relaciones contractuales. Cualquiera que sea la naturaleza de un contrato, las Corporaciones locales siempre intervienen como personas jurídicas, y por tanto como sujetos de derechos y obligaciones, unas veces de Derecho público y otras, como ocurre en los casos cuyo objeto son los bienes de propios, de Derecho privado. En ambos casos, proceden como Entidades administrativas, pues no dejan de serlo nunca en el desarrollo de lo que la doctrina ha venido en llamar actividad administrativa de Derecho privado, de la que un ejemplo puede muy bien ser los contratos que examinamos.

Algunas de las sentencias que hemos recogido emplean el término poder social, que impone y manda más que contratá, dejando a salvo sus prerrogativas, vestigio del principio de la Administración-Poder, lo que en esencia no es otra cosa que aplicar los conceptos de subordinación, que parte de la doctriną 
emplea, dado el carácter de desigualdad de partes sobre que se monta el contrato administrativo.

La otra parte contratante puede ser, bien un particular, persona jurídica o natural u otra Entidad pública. Precisamente es en materia de bienes privados donde más abundan, según los autores que se han ocupado de este problema, los llamados contratos entre Entidades públicas. Estas Entidades pueden pertenecer, bien a la Administración central, a la local o al complejo orgánico, que comprende la Administración institucional.

Un ejemplo legislativo lo encontramos en el Decreto del $\mathrm{Mi}$ nisterio de la Gobernación de 30 de septiembre de 1948, cuyo artículo $1 .^{\circ}$ faculta a las Diputaciones, Cabildos insulares y Ayuntamientos para ceder gratuitamente o con un canon reducido, a las Delegaciones Nacionales del Frente de Juventudes y Sección Femenina, bienes inmuebles de propios con objeto de instalar en ellos campamentos, etc., debiendo en todo caso obtener autorización previa del Ministerio de la Gobernación, para efectividad del acuerdo corporativo correspondiente.

En el reciente Reglamento para aplicación de la legislación sobre Arrendamientos rústicos aprobado por Decreto de 29 de abril de 1959, se plantea un caso susceptible de calificarse como contrato entre Entidades administrativas. Su artículo 36, párrato 1, dice que las Asociaciones expresadas en el artículo 32. (Sindicatos agrícolas, Grupos sindicales de Colonización), tendrán derecho preferente para arrendar en régimen de arrendamiento colectivo, las siguientes fincas: a) Las pertenecientes al patrimonio rústico municipal, hállense o no arrendadas, siempre que no estén sometidas a un régimen de aprovechamiento comunal. Y el artículo 16, párrafo 6, concede el derecho de retracto en la venta de la totalidad de una finca cedida en parcelas a varios arrendatarios, a favor de los Grupos sindicales de Colonización, siempre que estén integrados por la tercera parte, como mínimo, de los colonos de la tierra.

El Tribunal Supremo se ha pronunciado, en una ocasión sobre el particular, en sentencia de la entonces Sala 5 de lo social de 11 de febrero de 1957 , dictada en recurso de revisión, interpuesto al amparo de la Ley de 28 de junio de 1940 por el Grupo sindical de la villa de $S$. contra el Ayuntamiento, para que 
se declare el derecho preferente, que según hemos visto, le corresponde, y se otorgue el contrato conforme a las condiciones que determine la propia sentencia. Es, pues, un contrato civil entre dos Entidades públicas, civil por el objeto, sometido al Derecho civil y del que conoce, no la Jurisdicción Contenciosoadministrativa, sino aquella a la que por razones de tipo económico-sociales le está atribuído.

Respecto del primer ejemplo que citábamos, la cuestión es distinta, y adelantando algo de lo que más tarde nos ocuparemos con más detenimiento al tratar del elemento objetivo, opinamos que el criterio que proclamábamos al principio del trabajo: por regla general los contratos sobre bienes de propios son civiles, sufre una excepción. En efecto, esta excepción consiste en el destino que se dé a los bienes contratados. Cuando como aquí ocurre, se tiende a un fin susceptible de calificarse como servicio público, el contrato es administrativo.

Junto a los sujetos contratantes, dentro de los elementos subjetivos, hay que encuadrar a aquellos que, no siendo partes, intervienen o pueden intervenir por razón de su preeminencia con respecto a las Corporaciones locales.

Al referirnos a los bienes de propios, hemos hablado de los poderes de tutela que corresponden a los órganos centrales sobre la actividad de las Corporaciones como Entidades descentralizadas. Uno de estos poderes limitados consiste en la necesaria autorización del contrato, en determinados casos, por los organismos competentes.

La Ley municipal de 1877, en su artículo 85, apartados 2) y 3), preceptuaba la aprobación del Gobernador, oyendo a la Comisión provincial, para la enajenación y permuta de edificios municipales inútiles para el servicio público a que estaban destinados y créditos particulares a favor del pueblo, y todos los contratos relativos a todos los demás bienes inmuebles del Municipio, derechos reales y títulos de la Deuda pública.

Ni los Estatutos municipal y provincial de Calvo Sotelo, ni la Ley municipal de 1935, siguiendo tendencias más descentralizadoras, recogieron esta limitación.

Vamos a delimitar el contenido y límites de la aprobación a la luz de là Jurisprudencia. 
1). ¿En qué consiste? Desde antiguo, se dice: $\dot{v}$. gr.; por el Decreto resolutorio de Competencia de 18 de junio de 1866 "que la aprobación de los contratos sobre bienes de propios, en que los Ayuntamientos obran como personas juridicas, es una forma externa de darles validez o nulidad, pero no convertirlos en actos administrativos".

2) Su finalidad, según el $R$. D: Sentencia de $: 24$ de octubre ae 1888, que declaró la nulidad del contrato celebrado por un Ayuntamiento y aprobado por el Gobierno, por: el que aquél cedia cuantas hectáreas podían resultar de más en los terrenós procedentes de sus propios, es determinar si son dichas ventas perjudiciales o ventajosas a los intereses públicos..., por lo que no pueden las municipalidades enajenarlas sin autorización del Gobierno, previo expediente donde se justifique la utilidad, necesidad y límite.

3) La aprobación debe hacerse por los órganos que taxativamente señala la Ley. Así se declara carente de efícacia la realizada por la Diputación (D. de Competencia de 28 de diciembre de 1880). Sin embargo, hay que advertir, como nos dice la sentencia de 24 de febrero de 1915 , que en Navarra es preceptiva la autorización de là Diputación foral, que ha sustituido al Consejo del Reino.

4) La falta de aprobación se sanciona con la nulidad del contrato. No sólo por el mandato general contenido en el artículo 4. ${ }^{\circ}$ del Código civil, que es de aplicación plena al caso (recordemos que estamos en presencia de contratos civiles de la Administración), sino por la ausencia de uno de los cuatro requisitos que para la validez y eficacia de los contratos señala el artículo $1 .^{\circ} \mathrm{del}$ Reglamento de Contratación local: incumplimiento de formalidades exigidas por las disposiciones vigentes (no olvidemos que dicho Reglamento se aplica por lo menos en cuanto a su celebración, normas que los regulan tanto los contratos civiles como los administrativos que llevan a cabo las Corporaciones locales). A mayor abundamiento, citamos las sentencias: Sala 1 de 4 de marzo de 1904, "la capacidad jurídica de los Ayuntamientos para contratar como personas civiles está limitada en los casos que señalan las reglas 2 y 3 , artículo 85 , Ley municipal, no pudiendo, en su virtud, tales estipulaciones tener trascendencia ju- 
rídica entre las partes cuando hayan recibido dicha aprobación,: ni. por lo tanto, la cesión de. intereses acordada por un Ayuntamiento para gestionar la entrega de láminas de propios". Más recientemente, la Sala 4 en sentencia de 25 de noviembre de 1957 . Geclara la inexistencia de derechos administrativos preestablecidos entre dos Ayuntamientos contratantes, por falta de autorización del Ministerio de la Gobernación.

ij 5) La subsanación de este vicio o defecto, sólo puede verifi-. carse por la observancia del requisito.

$\because 6):$ El contrato llevado a cabo en esa condición no produce ningún efecto, v. gr.: una Resolución de la Dirección General. de los Registros de 3 de junio de 1927 niega la posibilidad de inscripción en el Registro de la Propiedad, de la escritura de venta de propios, otorgada por el Ayuntamiento sin la aprobación del Gobierno. En jdéntico sentido otra Resolución de la Dirección. General de Registros de 18 de septiembre de $\mathbf{1 8 9 5 .}$

\section{B) Elementos objetivos}

Entre los distintos criterios para la distinción y consiguiente calificación de los contratos en los que interviene la Administración pública, ya hemos advertido del criterio objetivo, decisivo, según la doctrina y la Jurisprudencia, frente a la insuficiencia de otros elementos.

Repetimos aue, como principio general, serán civiles todos aquellos contratos que tengan por objeto un bien de los llamados de propios, y decimos en principio, puesto que no deja de haber excepciones, que en más de una ocasión han producido duda sobre su naturaleza, con el consiguiente problema.de determinar la jurisdicción competente para el conocimiento de las cuestiones que surgen acerca de los mismos. La cuestión tiene gran impor-: tancia desde el punto de vista de la economía procesal.

En algunos casos basta la naturaleza del bien para la calificación del contrato. Son éstos los casos de menos complejidad. Así, sentencia de 26 de octubre de 1897, cesión o arriendo de terrenos otorgada por una: Diputación; sentencia de 5 de noviem- 
bre de 1895, cesión de parcelas; R. D. de Competenciá de 14 de octubre de 1898, carácter civil de las cuestiones de reivindicación como de propiedad particular de los terrenos cedidos por tal concepto; sentencia de 27 de enero de 1928, cesión de solares que "constituye contrato civil, pues trátase de una cuestión de propiedad derivada de la adquisición y posesión en que de los solares que le fueron vendidos a aquella se encuentra; su conocimento incumbe a la Jurisdicción ordinarian; sentencia de la Sala 4 de 22 de diciembre de 1950, contrato de ventas de basuras entre un Ayuntamiento y una Sociedad particular que ipresenta las apariencias de civil, faltando las que pudieran obligar a catalogarle como administrativo, y es visto que el Ayuntamiento carecía de facultades o potestad para tomar determinaciones enderezadas a hacer efectivo el cobro por sí propio, debiendo haber acudido a los Tribunales de la Jurisdicción ordinaria"; también la Sala 4, en sentencia de 22 de diciembre de 1956, en apelación interpuesta contra acuerdo del Ayuntamiento por el que se daba por resuelto el arrendamiento de un chalet de verano, propiedad del Ayuntamiento: "los acuerdos de dicha Corporación no correspondían a sus facultades regladas, sino que obraba en el ámbito de dicho orden como sujeto de derechos y obligaciones a desenvolver en la vía adecuada, y por consecuencia se desprende la improcedencia de haberse acudido a dilucidarla ante esta Jurisdicción".

Pero en otros casos se hace preciso al Tribunal Supremo volver al criterio de la obra o el servicio público inmediato o directo, al cual pueden estar destinados los bienes, y que altera la naturaleza del contrato.

a) Parte de la doctrina ha elaborado la llamada teoría de los contratos instrumentales o de medios. Según ella, es preciso deslindar el objeto mediato o inmediato sobre el que se pacta, para llegar a la conclusión de si nos encontramos ante un contrato público o privado.

Con frecuencia se adquieren o se arriendan por ias Corporaciones bienes para ser destinados posteriormente, en virtud de un segundo contrato, a una obra o servicio público. 
Aquél es un contrato civil, porque aunque una de las partes: sea la Administración y el objeto un bien privado, la finalidad: inmediata no es la ejecución de una obra o la prestación de un servicio público, sino allegar el medio que, en su día, será destinado a tal efecto. Además, el otro contratante queda por completo al margen de la finalidad administrativa que se pretende lograr. En este sentido se pronuncia el Tribunal Supremo. (Sala 1), en sentencia de 5 de febrero de 1931, considerando civil la compra-venta de un inmueble destinado a Casa-cuartel de la Guardia Civil, y en otra ocasión, sentencia de 25 de octubre de 1951, támbién la Sala 1 se manifiesta en análogo sentido: El actor dedujo demanda contra el Ayuntamiento sobre nulidad de contratos para venta de terrenos destinados a construcción de un estadio municipal. El Ayuntamiento formuló incidente de previo y especial pronunciamiento, pues, estimando que los contratos eran de carácter administrativo, se daba la. incompetencia de jurisdicción. El Tribunal Supremo rechazó la incompetencia, considerando que la base para resolver este recurso es determinar si la cuestión planteada es civil o administrativa, "...los contratos de autos constituyen una compraventa de terrenos, que es civil...", "el objeto directo es la compra-. venta y no la obra o el servicio público, y nada supone en contra de lo dicho el destino exclusivo de los terrenos a estadio, porque esto no es más que fijarles el destino que ha de dárseles, pero no altera la naturaleza jurídica del contrato, porque no. lo transforma de ser uno de compra-venta en otro de obras o serviciosn.

Por el contrario, cuando se tiende de modo inmediato o directo a la prestación de un servicio público o a la ejecución de una obra de tal indole, aun tratándose de bienes privados, el contrato es administrativo.

Así se deduce de varias sentencias: 28 de septiembre de $\mathbf{1 8 8 6}$, "el contrato que lo motiva no tuvo por objeto el mero arrendamiento de una barca de pasaje, sino que se dirigia a atender un servicio de utilidad pública, por más que para emprestarlo se empleara una barca propiedad de la Corporación, es visto que 
en este caso la Corporación no obró como administrador de sus bienes propios y en beneficio exclusivo de ellos..., la barca establecida por el Ayuntamiento en el río no era ni significaba otra cosa que la continuación del camino público, que a falta de puente une las dos márgenes del río..., y teniendo además por objeto el contrato, directo e inmediato, un servicio de utilidad pública como lo es, entre otros, el pasaje de correos y pliegos de las autoridades y que afectan a fondos del presupuesto municipal, toda cuestión sobre ellos ha de ventilarse ante la Jurisdicción contencioso-administrativa».

Otro caso de contrato de permuta, es al que se refiere la sentencia de la Sala 3 de 6 de julio de 1928: Se concede autorización para ocupar ciertos terrenos de propios para construir un canal para aprovechamiento de un salto de agua, a cambio del suministro gratuito de cierto número de lámparas eléctricas de cierta intensidad y se considera administrativo, rpuesto que con él se trata de subvenir a un servicio de la importancia del alumbrado públicon.

b) Por lo que se refiere a los montes de las Corporaciones, sin entrar a dilucidar el problema tan discutido de su naturaleza demanial o patrimonial, digamos únicamente que para algunos es un típico ejemplo de la llamada escala de la dominialidad, el Tribunal Supremo en sentencia de 14 de marzo de 1956 rechaza el criterio sustentado por la Corporación de que al tratarse de bienes de propios, estaba ante una cuestión civil, "si bien los montes cuyo aprovechamiento se subastó no eran de uso público, sino patrimoniales destinados a satisfacer necesidades del Ayuntamiento..., por ser público el interés que la riqueza forestal ofrece y no existir incompatibilidad en que, con arreglo al Código civil, sean bienes privados y tengan a la vez para el Derecho administrativo condición de públicos..., de donde se infiere que no tienen carácter civil los contratos motivos de este pleito, al ser público el objeto sobre el que recaen".

Sin embargo, con anterioridad a la actual legislación de montes y a la sentencia citada, tenemos otra de la Sala de lo Contencioso del Tribunal Supremio de fecha 17 de abril de 
1915, en que califica como civiles los contratos de aprovechamiento de resinas celebrados entre dos Ayuntamientos propietarios de dos tercios del dominio útil de unos montes, y un particular a quien corresponde las dos terceras partes del dominio directo y es dueño en plena propiedad de la tercera parte restante.

c) Respecto de otros bienes rústicos patrimoniales no comunales y.sin una finalidad pública, rige el principio general. Por eso, no dejamos de manifestar cierta perplejidad ante un fallo de la Sala 4 del Tribunal Supremo de 7 de noviembre de 1947: El Ayuntamiento de Randa cedió el aprovechamiento de dos majadas que tenían el concepto de propios a don $\mathrm{X} \mathrm{X}$, quien. en 1937, fundándose en que el aprovechamiento de pastos y montanera era imposible a causa de la guerra, solicitó de la Comisión gestora una rebaja del precio, lo que le fue denegado. El Tribunal Supremo considera «que es preciso dejar sentádo que el contrato está sin género de dudas comprendido dentro del ámbito funcional que señala la Ley de $\mathbf{1 5}$ de marzo de 1935, sin que el hecho de que se trate de un contrato administrativo, pueda ser causa de estimar aplicable al mismo dicha Ley. Es innegable la aplicación del artículo 8...".

Aquí tenemos: 1) cesión de bienes privados; 2) ausencia absoluta de finalidad pública; 3) se declara el sometimiento a la legislación civil y, sin embargo, se considera administrativo el cöntrato, y 4) conoce del fondo del asunto la Sala 4, o sea, de lo Contencioso-administrativo.

iSi es administrativo, cosa que no vemos claro, ¿hasta qué punto le es aplicable la Ley de Arrendamientos rústicos, que está pensada y destinada a regular relaciones privadas? No es que no concibamos un contrato de arrendamiento administrativo, pero no sometido a normas civiles, sino a un régimen que, a consecuencia de la propia naturaleza -obra o servicio público-, estaría dominado precisamente por cláusulas exorbitantes del Derecho común.

Además, se viola el artículo $4 .^{\circ}$ de la entonces vigente Ley de 10: Contencioso-administrativo. 
d) Otra de las materias que puede dar lugar a confusiones es la relativa a bienes relacionados con la ordenación urbana.

Separemos de un lado los terrenos sobrantes de la vía pública o parcelas no utilizables definidas por el artículo 7. ${ }^{\circ}$ del Reglamento de Bienes, como aquellas porciones de terreno propiedad de las Entidades locales, que por su reducida extensión, forma irregular o emplazamiento, no fueran susceptibles de uso adecuado. Pueden enajenarse, constituyendo su enajenación un contrato civil, pues "no se trata de bienes de uso público" (sentencia de la Sala 4 de 27 de junio de 1936). Hay que precisar que una cosa son las parcela sobrantes, y otra la misma vía pública. (Resolución de la Dirección General de Registros de 18 de septiembre de 1895).

En el caso de que los bienes estén más o menos directamente relacionados con una reforma urbana, la idea finalista de la obra o el servicio público, juega, como en los casos anteriores, un papel decisivo.

Así, no son administrativos los contratos de permuta en virtud del cual se transfirió al. Ayuntamiento de S. una parcela de terreno que la Corporación proyectaba destinar a la apertura de dos calles, a cambio de dos parcelas que el Ayuntamiento había de entregar, y así resulta que la relación contractual, aun examinada con vistas únicamente a la finalidad perseguida por una de las partes, no tenía por objeto inmediato la apertura de las calles, sino la adquisición de un elemento preciso para llegar a la ejecución de la obra, por lo que el contrato reviste carácter civil, puesto que por su causa o recíproca entrega de parcelas, entra dentro de la esfera del Derecho privado (sentencia de la Sala 1 de 28 de diciembre de 1942), y la Sala 4 en sentencia de 26 de mayo de 1953, dice que el contrato celebrado por el Ayuntamiento de L., cuya nulidad se pretende por el demandante, es el de venta de solar propiedad de aquél para la construcción de un edificio cor ciertas y determinadas condiciones suntuarias, pero sin que en forma alguna sea para destinarle a servicio público, por lo que no ofrece duda su carácter civil. Condiciones 
que no desvirtúan en lo más mínimo su carácter de bien patrimonial de propios:

Un punto que no deja de ser interesante es el referente a la situación contractual en que se encuentra la Administración pública con respecto a los inquilinos de inmuebles expropiados por razones de urbanismo o por otras de finalidad pública.

¿Qué naturaleza tiene dicha relación entre la Administración que por la expropiación se convierte en propietaria y los arrendatarios? ¿Es civil o administrativa? ¿Qué poderes competen a los’ organismos locales? ¿Por qué vía pueden hacerlos efectivos?

Con anterioridad al Reglamento de Bienes, hemos encontrado dos soluciones dispares en sendos Decretos Resolutorios de Competencia.

En el primero de ellos, de fecha 21 de enero de 1928, el Ayuntamiento expropiante requirió al inquilino para que en plazo de un mes desalojara el garaje en el edificio expropiado, fijándole indemnización. Este entendió que no podía ser desalojado sin ser previamente vencido en juicio de desahucio, y acudió al Juzgado municipal. El Ayuntamiento requirió al Juzgado, fundándose en que siendo administrativo el procedimiento de expropiación, esta condición alcanza a los incidentes que surgen con inotivo del expediente: "la cuestión planteada es de naturaleza civil, por tratarse de derechos y obligaciones surgidos por un contrato de arrendamiento independiente de la expropiación, y en el cual se subrogó el Ayuntamiento al adquirir el inmueble en los derechos del antiguo propietario y también en sus obligaciones, por lo que no puede substraerse a las jurisdicciones competentes para entender las incidencias de dicho contrato por el hecho de la subrogación", concluye atribuyéndole a la Jurisdicción.

La postura contraria se mantiene en el también Decreto Resolutorio de Competencia de 5 de octubre de 1954. La presentë cuesstión surge entre la Audiencia de V. y el Ayuntamiento de A:, à reclamar la primera para el conocimiento de los Tribunales la resolución del contrato de arrendamiento y desahucio de los ocupantes de una finca exprópiada por el último, a los que pre- 
tende desahuciar por su propia autoridad: "El espíritu de la Iey de Régimen local, en su intención de reforzar la acción de los organismos administrativos, encomienda la ejecución de los desahucios, sin que aparezca claro que sólo quiera referirse a los meros actos ejecutivos, descartando el acto declarativo a la vía de la Administración.

"Que siendo esta Ley posterior, habrá que seguir lo en ella dispuesto, si es que se entiende que basta con esa declaración del artículo 151, y que no hace falta que se le dote de un singular desarrollo reglamentario, y que a ello inclina la consideración de que tratándose de un inmueble expropiado para la reforma de una vía pública, es un bien de propiedad del Municipio, de uso público, sobre el que no pueden existir relaciones de Derecho privado, siendo sólo en la esfera del Derecho administrativo donde pueden surgir problemas acerca de él, y concluyendo que el cumplimiento de un acuerdo de expropiación por causa de utilidad pública es efectivo por vía administrativa, independientemente de que quien ocupa el inmueble sea su anterior propietario, arrendatario o mero retentor."

A partir de la publicación del Reglamento de Bienes, y según su artículo 108 "la expropiación forzosa de fincas rústicas - urbanas, terrenos o edificios, producirá la extinción de los arrendamientos y de cualquiera otros derechos personales relativos a ocupación de las mismas", y en el párrafo tercero preceptúa que “los titulares de los derechos de ocupación extinguidos serán desahuciados conforme a las normas del presente títulon.

e) Cuestión muy debatida en numerosos fallos jurisprudenciales es la referente a los bienes de propios destinados al público, como son los hoteles, teatros, cines, plazas de toros, etc.

Distingamos que una cosa es el destino al público y otra muy distinta el que en sí constituyan un servicio público, diferencia que apreciamos con mayor nitidez si comparamos éstos con aquellos otros de particulares destinados al público (servicio de taxis, comercio en general, etc.).

El Reglamento de Bienes los califica a éstos y a otros análo- 
gos, en bienes de dominio público en su artículo $4 .^{\circ}$, párrafos $a$ ) y $b$ ), de donde les consideraríamos excluídos de nuestro estudio. Pero creemos que en casos como el presente, el texto reglamentario ha sido excesivo en la calificación de los bienes, atrayendo a la esfera pública objetos que, por su naturaleza, y prescindiendo de la declaración del Reglamento, son privados o patrimoniales.

El Reglamento de Bienes, se ha dicho, como el de Contratación, "responde a una mentalidad subjetivista, que sólo admitiria siempre y cuando se suprimiera la dualidad de jurisdicciones, aunque no la de regímenes".

Vamos a examinar la Jurisprudencia para formular a su luz las conclusiones pertinentes.

$\left.a^{\prime}\right)$ Instalación de restaurantes y bares en recintos públicos.

Estos contratos se consideran administrativos, más que por el servicio que se presta, por la ocupación que suponen de un lugar de dominio público. Así lo considera el R. D. de Competencia de $S$ de octubre de 1889 , contrato celebrado entre el Presidente de la Diputación de C., como Presidente de la Comisión Ejecutiva de la Exposición Marítima Nacional, y don $\mathrm{X} X$, para construir un edificio destinado a restaurante en el recinto de la Exposición, y debiendo abonar por el terreno 20 pesetas diarias.

El hecho de que la explotación de dichos establecimientos se realice por concesión de la Administráción pública y la diferencia con el arriendo, nos brinda el examen de una interesante y reciente sentencia de la Sala 1 de fecha 2 de junio đe 1958. El Ayuntamiento de Barcelona cedió para explotarlo el edificio denominado "Restaurante del Parque de la Ciudadelai,, propiedad de la Entidad, a don X X., el cual posteriormente dedujo demanda contra el Ayuntamiento sobre declaración de que era un contrato de arrendamiento de local de negocio, y debe entenderse prorrogado al amparo de la Ley de Arrendamientos urbanos.

El Tribunal Supremo, en sus considerandos, dice que no es 
arriendo, sino concesión, "puesto que no es consecuencia directa de un pacto entre los contratantes, sino que es objeto de un expediente administrativo, en el que se acordó una subasta que se anunció debidamente mediante un pliego de condiciones para la subasta, y por tanto, se adjudicó al mejor postor, y una vez hecho esto, fue cuando se otorgó la correspondiente escritura, a la que por determinación expresa de las partes se dió el rombre de concesión a todos los efectos legales oportunos, y que sea secuela natural de la cláusula 18 del pliego de condiciones, en el que se decía que, dado el carácter de concesión administrativa que tiene el presente contrato, el concesionario acepta tal carácter a todos los efectos oportunos; por lo que el contrato tiene el carácter de concesión que le dieron las partes...", "y en cuanto a lo que se afirma que el contrato no tenía ni podía tener la calificación de servicio público, baste indicar el artículo 102 de la Ley municipal que comprende cuanto significa interés del Municipio y en particular: de las materias que según su apartado $f$ ) se refieren a parques $y$ jardines, en cuyo sentido es indudable que se encontraba el Parque de la Ciudadela $y$, por tanto, es claro que el servicio de bar debía sacarse a subasta, sin que tuvieran que cumplirse los requisitos de la Ley de Arrendamientos urbanos en cuanto se refiere a los locales de negocios". En primer lugar afirma que "los derechos que surgen no son consecuencia de un pacto entre las partes, sino consecuencia de un expediente administrativo en el que se acordó la subastan, etc.

1) Cualquiera que sea la tan discutida naturaleza jurídica de la concesión acto unilateral (acto mixto reglamentario y contractual), lo cierto es que siempre hay un pacto más o menos encubierto y del cual nacen derechos entre concedente y concesionario. 2) No es privativo de este tipo de negocios jurídicos el expediente administrativo, la subasta y el pliego de condiciones que desembocan en el otorgamiento de la escritura. Todos estos trámites son obligados para un contrato, sea concesión o arriendo, en que intervienen como parte una Corporación local como preceptúa el Reglamento de Contratación. 
3): Una determinada figura jurídica no es de tal o cual naturaleza porque lo digan o lo dejen de decir las partes, sino por su adecuación al tipo definido por el Derecho objetivo. Asi nos parece criticable la postura del Tribunal Supremo, al decir que el contrato tiene el carácter que le dieron las partes. Finalmiente, al calificar el servicio de bar como servicio público, aludiendo a la competencia que señala la Ley, se incurre en la confusión entre servicios públicos y funciones locales. No todo lo que regulan la Ley y los reglamentos son servicios públicos. Aquí faltan las caracteristicas esenciales de tal servicio: posibilidad de monopolio de hecho y ausencia de utilidad pública directa.

Nosotros diriamos, que más bien se trata de servicio destinado al público mediante la utilización de bienes de dominio público. De donde concluímos que, el contrato en cuestión no es administrativo tanto por haberse realizado por concesión, ni por ser un servicio público, cuanto por significar una ocupación dèl dominio público.

\section{b') Salas de espectáculos.}

Por la propia naturaleza de bienes privados, todo contrato sobre ellos es civil. Así lo reconocen las sentencia de 30 de octubre de 1909 referente al arrendamiento del Teatro Principal de Zaràgoza. Como corisecuencia, tienen también carácter civil y no administrativo las designaciones o nombramientos de personal de las Corporaciones en dichos locales, v. gr., la sentencia de 24 de octubre de 1951 'wel acuerdo de designar un gestor artístico de los espectáculos públicos en el Teatro Municipal, es el ejercicio de un acto de administración en un bien patrimonial y cae fuera del concepto de servicio público, puesto que no envuelve un contrato administrativo por su objeto, que en este caso es privado. El Ayuntamiento tenía competencia por razón de la materia para acordar la designación de un gestor artístico, ya que se trata de un acto de administración de un bien patrimonialı. 
¿Qué tipo de contrato civil revisten? Normalmente sé tratä de arrendamiento de industria y no de locales de negocio. Otras veces, y no siendo en nuestro ordenamiento jurídico, la contratación un sistema de numerus clausus, se puede y debe reconocer la existencia de contratos atípicos mixtos en sentido lato. Así ocurre en el caso planteado ante el Tribunal Supremo por la Diputación de Zamora y fallado en sentencia (Sala 4) de 27 de junio de 1958.

Se refiere a la construcción y explotación del Teatro Nuevo. "En él aparecen elementos de un contrato de arrendamiento de un solar, y lo sobre él existente mediante el pago de cierta cantidad anual. mas en conexión con ellas se dan elementos de un contrato de ejecución de obra, el Teatro, con todos los requisitos y exigencias de la contratación administrativa: adjudicación por subasta, concurso, depósito provisional, aprobación de los planos por la Comisión provincial, y, sobre todo, remisión a las normas de contratación local; asimismo se da una concesión de explotación del Teatro como sala de espectáculos durante plazo determinado, con posibilidad de subarriendo a otras personas, y con dos limitaciones : ceder dos días cada año el Teatro a la Corporación para funciones benéficas, y el uso de un palco para los Diputados".

En cuanto a las normas alegables ante los Tribunales, la Sala de lo Civil del Supremo, en sentencia sobre resolución del contrato de arrendamiento del Teatro Principal de Palma de Mallorca, propiedad de la Diputación provincial de Baleares, estima que no es "dable alegar ni en el recurso de casación ni en el de injusticia notoria la infracción de normas que se refieren a materias extrañas a la competencia de esta Sala, cuyo cometido debe limitarse a las cuestiones de Derecho civil, y por ello la Jurisprudencia ha rechazado constantemente los recursos en disposiciones de carácter administrativo...) (S. de 23 de octubre de 1957).

Frente a la opinión de algún autor que tacha de ficticia la dualidad de jurisdicciones, observamos cómo el Tribunal Su- 
premo mantiene que es algo más sustancial de lo que por los mismos se ha sostenido.

Ahora bien, dado que el Reglamento de Contratación vigente unifica el tratamiento, tanto para los contratos civiles como para los administrativos, estimamos que, al menos, las normas de éste que se refieran a la celebración de contratos, pueden y deben ser alegadas si se consideran infringidas ante los Tribunales civiles.

Frente a esta doctrina bastante uniforme respecto a la naturaleza privada, se sienta el principio contrario por una sentencia de 20 de marzo de 1929 , referente a la cesión del Teatro Real de Madrid. "La cesión del Teatro Real a un particular en virtud de concurso, no puede por sí solo considerarse arriendo por el mero hecho de denominarse asi en el anuncio de concurso, ni es contrato civil, sino administrativo, porque dicha cesión no la hizo el Estado como persona juridica, atenta sólo al interesado deseo de percibir los frutos civiles que por derecho pertenecen al propietario de un inmueble, sino obedeciendo al más noble y elevado propósito de procurar el mayor esplendor al arte musical, y ejercitando así una función de gobierno en servicio de la Nación de innegable utilidad pública, por todo lo cual no es posible sostener que el contrato sea civil".

"Tampoco se le puede considerar como arrendamiento por las actividaes que el empresario había de desarrollar con posterioridad a la toma de posesión, no sólo en cuanto se refiere a la conservación, sino a su limpieza, alumbrado, fijación numérica de los elementos artísticos, intervención del abono, fiscalización del gasto, etc..., porque tan manifiesta injerencia del supuesto arrendador en la conducta a seguir por el arrendatario supuesto..., contradice abiertamente la esencia y finalidad del arrendamiento."

De aquí que saquemos en consecuencia que cuando, por medio de estos teatros o cines, se tiende de una manera directa a la realización de una labor educadora de auténtica misión cultural que redunde en beneficio público, o que mantenga el nivel artístico y social del espectáculo, la finalidad se impone por 
encima de la naturaleza de los bienes y es, otra vez; la idea del servicio público la que nos sirve de piedra. de toque para determinar el sometimiento a uno u otro ordenamiento.

: $:$ Pero creemos que no basta esta idea finalista si no se añade un régimen especial de explotación en consonancia con dicho fin: social y divulgador. Los locales en cuestión han de funcionar:! de forma distinta a las empresas privadas. El ejemplo típico es el Teatro de la "Comédie Française", verdadero servicio público, ęn el que los actores son funcionarios de plantilla. Otro ejemplo más próximo lo encontramos en el Teatro Español, de Madrid. Este coliseo, perteneciente al Ayuntamiento de Madrid, fue cedido en arriendo para su explotación a la $\mathrm{Di}$ rẹcción General de Cinematografía y Teatro, imponiéndose una serie de condiciones: Representaciones de obras clásicas, dignidad en los montajes, sesiones de teatro infantil educativo con gratuidad para los alumnos de las Instituciones municipales, bonificación en los precios para estudiantes, precios más bajos que los demás teatros, de acuerdo con las subvenciones.

c') Razonamiento análogo podríamos hacer por lo que se refiere a hoteles de propiedad municipal, a la vista de dos sentencias recientes, que han sido objeto de comentarios monográficos: la sentencia (Sala 4) de 19 de diciembre de 1958, relativa al "Andalucía Palace", de Sevilla, cuyo arrendamiento se califica de civil por tratarse de bien patrimonial, no destinado a un servicio público, y la de 2 de marzo de 1959, también de la Sala 4 , la, cual se declara incompetente para conocer de la venta del "Hotel Playa", de Cádiz, por considerarla civil por su objeto. "Se trata de un bien consistente en un inmueble dedicado exclusivamente para hotel de viajeros y explotado como industria hotelera, inscrito en el Registro de la Propiedad como bien de propios... Es, pues, un contrato de venta de inmueble que no estaba deștinadc a obras ni servicios públicos, sino a una industria...n.

Como deciamos en los ejemplos anteriores si, con una finalidad de fomento del turismo y con un régimen especial para favorecer su afluencia a una determinada zona, una Corpora- 
cịón edifica o arrienda locales de hosteleria, estaremos en presencia de contratos administrativos y no civiles.

d') Las plazas de toros, que en muchas localidades pertenecen a los Ayuntamientos o a las Diputaciones, plantean el problema de si con motivo de festejos patronales, en los que por. lo arraigado de la afición no faltan los espectáculos de esta indole, puedan considerarse de interés público.

Con la Ley de Régimen local en la mano, y en su artículo 101, aue enumera la competencia municipal, podría aludirse a su apartado $f$, que menciona las fiestas religiosas y profanas tradicionales, pero no hay que confundir lo que puede ser competencia local con los servicios públicos locales.

Un Decreto de la Presidencia, Resolutorio de Competencia, es bastante claro a este respecto. Se plantea la competencia entre la Administración y la Jurisdicción ordinaria. Reclama un contratista ante el Juzgado el pago de las obras de reparación de una plaza de toros perteneciente a un Ayuntamiento, y requiere de inhibición a la Administración:

i....En la esfera legal y a efectos jurisprudenciales importa, atendiendo al objeto de distinguirlos por la obra o el servicio público. La construcción de una plaza de toros no puede nunca calificarse como obra o destinada a un servicio público..., que la Corporación no obró de otra manera que como titular de derechos y obligaciones de índole civil..., por lo que si ha producido lesión de derechos, como éstos son de carácter civil, a los Tribunales civiles corresponde esclarecer el caso..., el hecho de que las leyes municipales declaren de la exclusiva competencia de los Ayuntamientos lo relativo a embellecimiento dē las ciudades y esparcimiento del público. no quiere decir que atribuyan a aquéllos y luego a los Tribunales Contencioso-administrativos la jurisdicción para atender a toda suerte de reclamaciones sobre la materia...".

Esta naturaleza, civil, determina en un caso análogo que no pueda aplicarse el procedimiento de apremio administrativo, y que es competencia de la Jurisdicción ordinaria (D. Resolutorio de 21 de mayo de $\mathbf{1 9 5 5}$, en cuestión surgida entre la Audiencia 
Territorial de Granada y el Ayuntamiento de Melilla, al requerir la primera al segundo para que deje de conocer en el expediente administrativo incoado por débitos de un particular al Municipio, dimanantes de contrato de arrendamiento de la plaza de toros, celebrado entre ambos).

\section{C) Elementos formales}

El problema de la forma en la dualidad contrato civil-contrato administrativo, que durante largo tiempo sirvió como distinción entre unos y otros, lo consideramos secundario y accidental.

De una parte, porque hay contratos concluidos entre particulares, a los que se impone una determinada forma precep: tiva por las leyes civiles y mercantiles, y de otra porque a los mismos contratos civiles de la Administración se sujetan a forma lidades expresas.

Frente al principio espiritualista consagrado por el Código civil, el Reglamento de Contratación añade a los requisitos esenciales, además de los formulados en el artículo 1261 del Código civil, un cuarto que es el cumplimiento de las formalidades exigidas por las normas vigentes.

Esto es plenamente aplicable tanto a los contratos civiles como a los públicos, pues, son normas referentes a su celebración, como dice la disposición adicional 1 , por la que se mantiene el criterio tradicional, dejando sometido su contenido al Código civil.

Hasta la aparición del Reglamento, dicho principio sólo estaba formulado por la Jurisprudencia.

Posteriormente ha venido el Tribunal Supremo a matizar alguna cuestión surgida sobre el particular, v. gr.: que la adopción de subasta en la venta de un bien patrimonial en nada puede influir para estimar administrativo el contrato, pues ésta se puede celebrar también en los civiles (S. de la Sala 4 de 2 de marzo de 1959). 
Cualquiera de las formas que señala el Reglamento, no son privativas o características de un determinado tipo de contratos, sino que pueden emplearse en cada caso independientemente de su naturaleza. Lo afirmamos en contra de la sentencia' de 2 de junio de 1958, la cual afirma que la subasta es algo característico y único de las concesiones y no de los arriendos. Criterio que de admitirlo iría en contra de la aplicación del Reglamento a los contratos civiles. Además, la experiencia constante nos demuestra lo contrario.

- El defecto de forma, ya hemos dicho, cuando es esencial para: la validez del contrato, trae consigo la nulidad de pleno derecho dè mismo:

\section{D) Pérdida de efectos por anulación}

- Los contratos perfectos producirán los efectos propios según su naturaleza.

Hay varios supuestos de pérdida de los efectos. De ellos vamos únicamente a ocuparnos del caso de la anulación.

El artículo 2. ${ }^{\circ}$ del Reglamento de Contratación señala a las Corporaciones locales una competencia en la contratación que se extiende a la aprobación, etc..., y en último lugar a la posibilidad de acordar la resolución, rescisión o denuncia contractual. No se menciona para nada la potestad de anulación.

De acuerdo con la Jurisprudencia, podemos delimitar así la cuestión :

a) Esta potestad no corresponde en modo alguno a la Administración contratante: así lo afirma el $R$. D. en sentencia de 20 de diciembre de 1865: "las ventas de propios hechas por los Ayuntamientos no pueden ser anuladas por la Administración".

b) La Administración central tampoco puede, ni a título de órgano tutelante, anular dichos contratos: ulas facultades de las autoridades superiores en el orden jerárquico están limitadas a la inspección y vigilancia en la gestión de tales bienes, por. 
lo que no puede estimarse legítimo el acto administrativo que declare sobre la validez de tales contratos". (Decreto de 7 de abril de 1865 y Real Decreto de 14 de noviembre de 1878). En otra ocasión, el Gobernador civil anuló un contrato concluido por un Ayuntamiento, y a su vez el Gobierno dejó sin efecto el acuerdo del Gobernador, fundándose en que esta autoridad "no debió revocarlo, con tanto más motivo cuanto los derechos de un contrato sólo pueden ser explicados y contradichos por la Jurisdicción...n.

En otra ocasión (S. de 28 de junio de 1907) el Tribunal Supremo califica como de abuso de poder y la anula, la Real Orden del Ministerio de la Gobernación, por la que revoca un contrato defectuoso concluído por una Diputación: "a nadie más que a la Jurisdicción compete reparar la infracción cometida, que en otro caso no habría medio de subsanar con grave daño de la recíproca independéncia de poderes".

Otra sentencia de la Sala 3, del 17 de abril de 1915, declara que siendo civiles los contratos, no pueden ser legalmente anulados por la Administración..., y el Ministerio de Fomento no tenía ninguna competencia ni podía anularlos..."

c) La anulación corresponde a los Tribunales jurisdiccionales, y puesto que el artículo 12 del Reglamento de Contratación, aun en contra de la posición doctrinal de sus redactores mantiene la dualidàd de Jurisdicciones, será competente una u otra, según sea calificada de acuerdo con lo que hemos escrito arriba, la naturaleza del contrato.

Terminamos advirtiendo que adoptando la teoría del llamado acto separable, puede pretenderse la anulación de los actos administrativos preparatorios a la ejecución de un contrato, aunque éste sea civil, siendo entonces competente la Jurisdicción contencioso-administrativa. 